\title{
BMJ Open Association between rhinovirus wheezing illness and the development of childhood asthma: a meta-analysis
}

\author{
Lu Liu, Yilin Pan, Yanting Zhu, Yang Song, Xiaofan Su, Lan Yang, Manxiang Li
}

To cite: Liu L, Pan Y, Zhu Y, et al. Association between rhinovirus wheezing illness and the development of childhood asthma: a metaanalysis. BMJ Open 2017;7: e013034. doi:10.1136/ bmjopen-2016-013034

- Prepublication history and additional material is available. To view please visit the journal (http://dx.doi.org/ 10.1136/bmjopen-2016013034).

Received 14 June 2016 Revised 7 March 2017 Accepted 8 March 2017

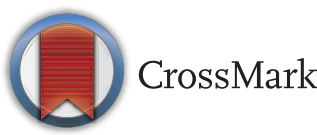

Department of Respiratory and Critical Care Medicine The First Affiliated Hospital of Xi'an Jiaotong University, Xi'an, PR China

Correspondence to Dr Manxiang Li; manxiangli@hotmail.com

\section{ABSTRACT}

Objective: The relation between early-life rhinovirus (RV) wheezing illness and later onset of wheezing/ asthma remains a subject of debate. Therefore, we conducted this meta-analysis to evaluate the association between RV wheezing illness in the first 3 years of life and the subsequent development of wheezing/asthma.

Design: Systematic review and meta-analysis. Methods: The PubMed, EMBASE, Web of Science, Chinese National Knowledge Infrastructure (CNKI) and Wanfang databases were systematically searched for studies published between 1988 and February 2017, and additional studies were found by searching reference lists of relevant articles. 2 reviewers independently extracted data and assessed the quality of each study. Results were pooled using fixed-effect models or random-effects models as appropriate.

Results: The meta-analysis included 15 original articles which met the criteria, while 10 articles reported the results of 4 longitudinal cohort studies with different follow-up periods. RV wheezing illness in the first 3 years of life was associated with an increased risk of wheezing/asthma in later life (relative risk $(\mathrm{RR})=2.00,95 \% \mathrm{Cl} 1.62$ to $2.49, \mathrm{p}<0.001)$. In subgroup analysis by age at follow-up, the association still remained significant in $<10$ years $(R R=2.02,95 \%$ $\mathrm{Cl} 1.70$ to $2.39, p<0.001)$ and $\geq 10$ years $(R R=1.92$, $95 \% \mathrm{Cl} 1.36$ to $2.72, p<0.001$ ).

Conclusions: The meta-analysis suggests an association between RV-induced wheezing in the first 3 years of life and the subsequent development of wheezing/asthma. Large-scale and well-designed studies that adequately address concerns for potential confounding factors are required to validate the risk identified in the current meta-analysis.

\section{INTRODUCTION}

Asthma is one of the most common chronic respiratory diseases in children with an increasing prevalence and financial burden worldwide. ${ }^{1}$ Risk factors for asthma are diverse, which include air pollution, passive smoking, genetic factors and others. ${ }^{2}{ }^{3}$ Several studies have shown that virus-induced wheezing in

\section{Strengths and limitations of this study}

- This is the first meta-analysis to examine whether rhinovirus-induced early wheezing increased the risk of childhood wheezing/ asthma.

- All the studies included had moderate-to-high qualities according to the Newcastle-Ottawa Scale (NOS)

- The number of studies and participants included in the present meta-analysis was relatively small.

- Only published studies with sufficient data were included, so the possibility of publication bias cannot be completely ruled out.

early life might also predict subsequent childhood wheezing/asthma. ${ }^{4-6}$ Historically, respiratory syncytial virus (RSV) has long been considered the most common aetiology. ${ }^{7}$ However, with the development of molecular virology technology during the past few decades, rhinovirus (RV) has been gradually recognised as a major pathogen causing acute wheezing in early life. ${ }^{89}$

RV, a positive-sense, single-stranded, non-enveloped RNA virus belonging to the family Picornaviridae, consists of more than 160 individual types that are classified into three species (A, B and $\mathrm{C}$ ) based on viral genetics. ${ }^{10}$ RV-related diseases are globally distributed, and usually have seasonal peaks in spring and fall in geographic regions with temperate climates. ${ }^{11}$ It was long thought that RV infection was limited to the upper airways where the temperature of mucosal surface was suitable for virus replication. ${ }^{12}$ Current evidence suggests that RV could also infect the lower respiratory tract and has been considered as a major aetiological factor for preschool wheezing illness. ${ }^{13-15}$ Approximately $20-40 \%$ of infants (under 1 year of age) with bronchiolitis have RV infection, increasing to about $50 \%$ of hospitalised wheezing children by 3 years. ${ }^{16}{ }^{17}$ Recently, several prospective studies have 
shown that early wheezing illness associated with RV infection is linked to increased risk of the subsequent development of wheezing or asthma. ${ }^{14}{ }^{15}{ }^{18-23}$ It is possible that RV infection is involved in the development of asthma through promoting airway inflammation and remodelling, and clinically significant RV infection might also help to identify children predisposed to asthma. ${ }^{24}$ However, other researchers think that RV does not increase the risk of asthma. ${ }^{25}$

The demonstration of a relation between RV-induced early wheezing and the development of later childhood wheezing/asthma, as well as a better understanding of the nature of this association, could have important implications for the prevention and treatment of asthma. To the best of our knowledge, no study has been published that has systematically reviewed the literature and synthesised the available evidence. Therefore, we performed a systematic review and meta-analysis of the existing evidence.

\section{METHODS}

The study was conducted according to the Preferred Reporting Items for Systematic Reviews and Meta-Analyses (PRISMA) guidelines. ${ }^{26}$

\section{Search strategy}

Two independent reviewers (LL and YP) searched the PubMed, EMBASE, Web of Science, Chinese National Knowledge Infrastructure (CNKI) and Wanfang databases to identify available studies published between 1988 and February 2017. The search terms used were (rhinovirus OR respiratory virus OR virus OR infection) AND (infant OR children OR child OR childhood OR adolescence) AND (wheezing OR asthma). A search strategy for each database was established with the help of a library expert of Xi'an Jiaotong University. An example of search details using EMBASE was shown in online supplementary table S1. There was no limit on language, sample size or population for minimising potential publication bias. Additional studies were found by searching reference lists of identified articles.

\section{Inclusion and exclusion criteria}

Studies were included in the meta-analysis that met the following criteria: (1) original article; (2) the maximum age at the time of wheezing was 3 years; (3) diagnosis of RV infection was virologically confirmed in all cases; (4) a follow-up period was included; (5) outcome of interest was wheezing/asthma (diagnosis was made on the basis of one of the following: physician diagnosis of wheezing/asthma, parents reported repeated episodes of wheezing or coughing, use of short-acting or long-acting $\beta$-agonists and/or controller medications, and exercise challenge test positive). Studies were excluded if they did not meet these inclusion criteria. Unpublished data were not considered. Study selection was achieved by two investigators (YZ and YS) independently and all the disagreements were resolved by discussion.

\section{Quality assessment}

The qualities of studies included in this study were independently assessed by two reviewers (XS and LY) according to the Newcastle-Ottawa Scale (NOS). ${ }^{27}$ We considered a study awarded $0-3,4-6$ or 7-9 as a lowquality, moderate-quality or high-quality study, respectively. Discrepancies were resolved by consensus and discussion.

\section{Data extraction}

Data from identified studies were extracted by two independent reviewers (LL and YP) using a standardised data collection form and then compared. Discrepancy was resolved by consensus or a third reviewer (YZ). For each included study, the retrieved data were the following: first author, publication year, study design, original country, the number of participants, age at enrolment in the study, age at follow-up and effect estimate (95\% CI). If a study reported several potential outcomes of interest (eg, asthma, wheezing and recurrent wheezing), the selection of the outcome was based on the following criteria (sorted by descending level of importance): (1) diagnosis by a physician was selected over parental assessment; (2) current respiratory status or respiratory status in the past 12 months was selected over cumulative outcome; (3) asthma was selected over wheezing.

\section{Statistical analysis}

Measures of association (HR or relative risk (RR) or OR) and their 95\% CI were extracted or derived by using data reported in the articles (unadjusted $\mathrm{RR}=\mathrm{P}_{1}$ / $\mathrm{P}_{0}, \mathrm{P}_{1}$ indicates the incidence of the outcome of interest in the exposed group and $\mathrm{P}_{0}$ in the non-exposed group).$^{28}$ The RRs were used as the common measure of association across studies. HRs were directly considered as RRs. Where necessary, ORs were transformed into RRs using the formula $\mathrm{RR}=\mathrm{OR} /\left(\left(1-\mathrm{P}_{0}\right)\right.$ $\left.\left(\mathrm{P}_{0} \times \mathrm{OR}\right)\right){ }^{28}$ The $\mathrm{P}_{0}$ values were shown in online supplementary table S2. This method of transformation has some limitations and can underestimate the variance of the RRs derived from the ORs. ${ }^{29}{ }^{30}$ We therefore performed a sensitivity analysis that excluded the studies in which this transformation was performed. We also compared the results applying the Miettinen test-based approach for calculating the variance of the natural logarithm of the RR (lnRR; variance $\operatorname{lnRR}=$ variance $\ln \mathrm{OR} \times(\operatorname{lnRR} / \operatorname{lnOR})){ }^{31}$

Meta-analysis was performed using Stata V.12.0 software (Stata Corp, College Station, Texas, USA). We used the 'metan' command in Stata to pool the lnRR. Forest plots were used to visually assess the RR estimates and corresponding 95\% CIs across studies. Heterogeneity among studies was calculated using the $\mathrm{Q}$ statistic (significance level of $\mathrm{p}<0.10)$ and $\mathrm{I}^{2}$ statistic $(>50 \%$ as evidence of significant inconsistency) ${ }^{32} \mathrm{~A}$ fixed-effects 
model was adopted when heterogeneity between studies was not significant. Otherwise, a random-effects model was used. Subgroup analysis was stratified by age at follow-up ( $<10$ years and $\geq 10$ years). Potential publication bias was assessed by using funnel plot and Begg's and Egger's tests, and $\mathrm{p}<0.05$ was considered significant. ${ }^{33} 34$

\section{RESULTS}

\section{Studies selected and their characteristics}

A total of 6504 studies were identified. Of them, 1173 were excluded for duplicates and 5224 were excluded after screening the titles and abstracts, leaving 107 studies for full-text review. Finally, 15 articles fulfilled our eligibility criteria and were included in this meta-analysis (figure 1). ${ }^{14} \quad 15 \quad 18-23 \quad 25 \quad 35-40$ All selected studies are cohort studies and in children under 3 years of age, with confirmed RV-associated wheezing and a defined outcome (later childhood wheezing/asthma). Ten articles report the results of four longitudinal cohort studies with different follow-up periods. $^{18} \quad 1922 \quad 25 \quad 35-40$ There are seven cohorts in Caucasians $^{14} \quad 18-20 \quad 22 \quad 23 \quad 25 \quad 35-40$ and two cohorts in Asians. ${ }^{15}{ }^{21}$ All studies were assessed by NOS and their score ranged from 6 to 8 , suggesting that the methodological quality was acceptable. The main characteristics of studies are summarised in table 1; more details about studies are shown in online supplementary table S2.

\section{Quantitative synthesis}

When a cohort study had several periods of follow-up, we used the values from the longest follow-up to perform overall analysis (nine studies ${ }^{14} 15$ 20-23 253536 were included). Heterogeneity of the studies was acceptable $\left(I^{2}=30.1 \%, p=0.178\right)$, and thus a fixed-effects model was used. The combined results showed that RV wheezing illness in the first 3 years of life was associated with increased risk of wheezing/asthma $(\mathrm{RR}=2.00,95 \% \mathrm{CI}$ 1.62 to $2.49, \mathrm{p}<0.001$; figure 2 ). When we included all relevant studies $(n=15)$ containing the same cohorts with different follow-up periods, the overall pooled results did not change ( $\mathrm{RR}=2.00,95 \%$ CI 1.71 to 2.33 , $\mathrm{p}<0.001)$. To evaluate whether the association between $\mathrm{RV}$ wheezing and development of wheezing/asthma would change with age, we included all the studies $(\mathrm{n}=15)$ to perform subgroup analysis stratified by age at follow-up. No significant heterogeneity was identified $\left(<10\right.$ years, $\quad \mathrm{I}^{2}=33.6 \%, \quad \mathrm{p}=0.13 ; \quad \geq 10$ years, $\quad \mathrm{I}^{2}=7.7 \%$, $\mathrm{p}=0.355$ ), and thus a fixed-effects model was used. The association still remained significant in $<10$ years $(\mathrm{RR}=2.02,95 \%$ CI 1.70 to $2.39, \mathrm{p}<0.001)$ and $\geq 10$ years ( $\mathrm{RR}=1.92,95 \%$ CI 1.36 to 2.72, $\mathrm{p}<0.001$; figure 3 ).
Figure 1 Flow chart of the process of selecting relevant studies. CNKI, Chinese National Knowledge Infrastructure; RV, rhinovirus.
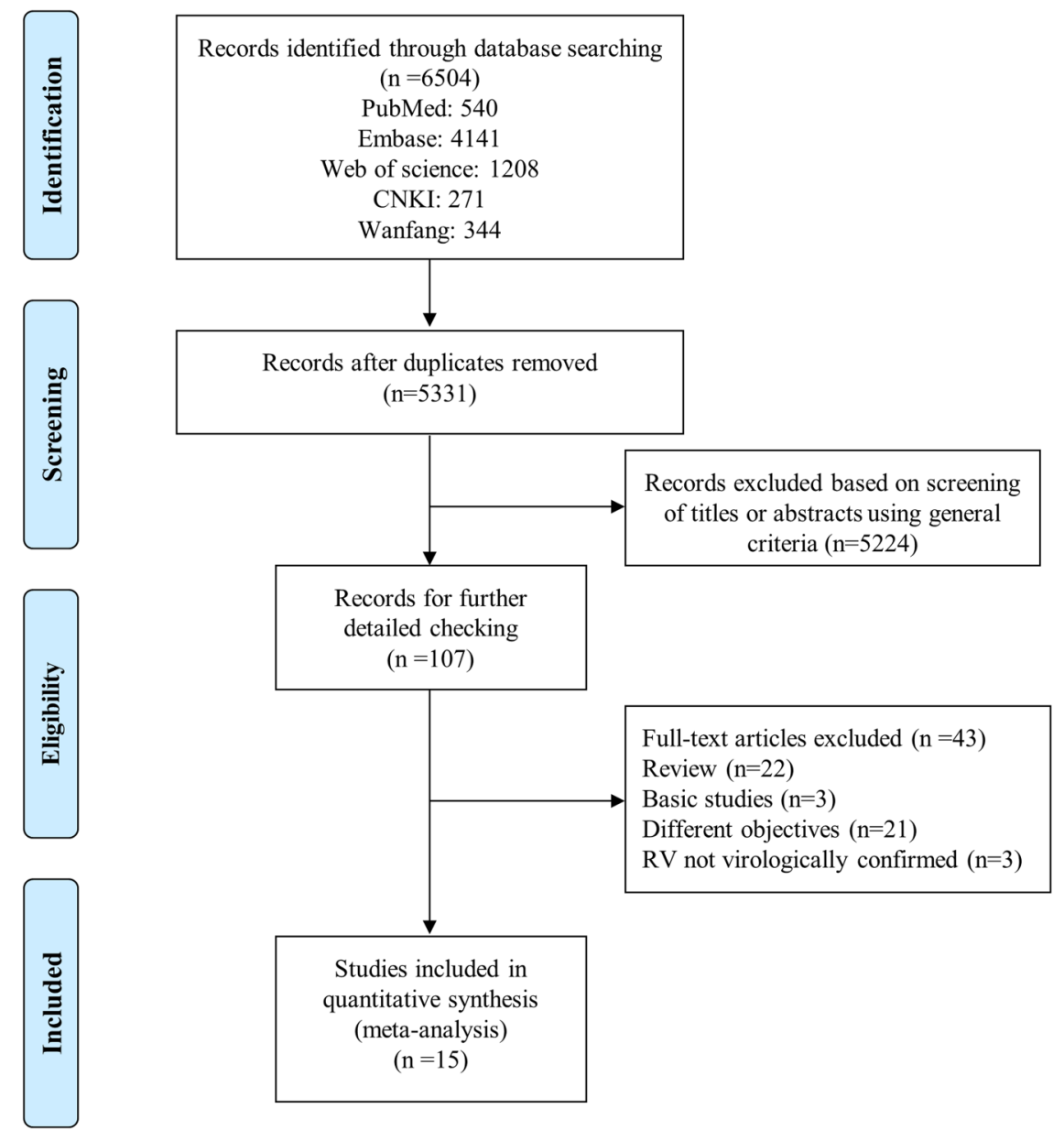
Table 1 Characteristics of studies included in meta-analysis $(n=15)$

\begin{tabular}{|c|c|c|c|c|c|c|c|c|}
\hline Study & $\begin{array}{l}\text { Published } \\
\text { year }\end{array}$ & Country & $\begin{array}{l}\text { Number of } \\
\text { participants }\end{array}$ & $\begin{array}{l}\text { Age at } \\
\text { enrolment in the } \\
\text { study (months) }\end{array}$ & $\begin{array}{l}\text { Age at } \\
\text { follow-up } \\
\text { (years) }\end{array}$ & Outcome & $\begin{array}{l}\text { Effect estimate }(95 \% \\
\mathrm{Cl})\end{array}$ & NOS \\
\hline $\begin{array}{l}\text { Kotaniemi-Syrjänen et } a{ }^{40} \text { (rhinovirus } \\
\text { wheezing illnesses study) }\end{array}$ & 2003 & Finland & 100 & $<24$ & $6-8$ & Asthma & OR 4.14 (1.02 to 16.77$)$ & 7 \\
\hline $\begin{array}{l}\text { Hyvärinen et al }{ }^{18} \text { (rhinovirus wheezing } \\
\text { illnesses study) }\end{array}$ & 2005 & Finland & 100 & $<24$ & $11-13$ & Asthma & OR 1.41 (0.4 to 4.94$)$ & 7 \\
\hline $\begin{array}{l}\text { Ruotsalainen et } a^{\beta 5} \text { (rhinovirus wheezing } \\
\text { illnesses study) }\end{array}$ & 2013 & Finland & 100 & $<24$ & $15-18$ & Asthma & OR 9.23 (2.17 to 39.31$)$ & 7 \\
\hline Lemanske et $a^{\beta 9}$ (COAST study) & 2005 & USA & 289 & Newborns & 3 & Wheezing & OR 10 (4.1 to 26$)$ & 8 \\
\hline Jackson et $a l^{19}$ (COAST study) & 2008 & USA & 289 & Newborns & 6 & Asthma & OR $2.8(1.4$ to 5.6$)$ & 8 \\
\hline Rubner et $a^{\beta 6}$ (COAST study) & 2016 & USA & 289 & Newborns & 13 & Asthma & OR 3.3 (1.5 to 7.1$)$ & 8 \\
\hline $\begin{array}{l}\text { Kusel et } a^{\beta 7} \text { (respiratory viral infections } \\
\text { study) }\end{array}$ & 2007 & Australia & 263 & Newborns & 5 & Asthma & OR 2.9 (1.2 to 7.1$)$ & 7 \\
\hline $\begin{array}{l}\text { Kusel et } a^{25} \text { (respiratory viral infections } \\
\text { study) }\end{array}$ & 2012 & Australia & 263 & Newborns & 10 & Asthma & RR 1.63 (0.77 to 3.45$)$ & 7 \\
\hline Midulla et $a^{\beta 8}$ (recurrent wheezing study) & 2012 & Italy & 313 & $\leq 11$ & $1-2$ & $\begin{array}{l}\text { Recurrent } \\
\text { wheezing }\end{array}$ & OR 3.3 (1.0 to 11.1$)$ & 6 \\
\hline Midulla et $a P^{2}$ (recurrent wheezing study) & 2014 & Italy & 313 & $\leq 11$ & $3-4$ & $\begin{array}{l}\text { Recurrent } \\
\text { wheezing }\end{array}$ & OR 3.1 (1.0 to 9.4$)$ & 7 \\
\hline Lukkarinen et $a R^{20}$ (the Vinku Study) & 2013 & Finland & 111 & $3-35$ & 7 & $\begin{array}{l}\text { Recurrent } \\
\text { wheezing }\end{array}$ & HR 3.54 (1.51 to 8.3$)$ & 7 \\
\hline van der Gugten et al $^{14}$ (WHISTLER) & 2013 & $\begin{array}{l}\text { The } \\
\text { Netherlands }\end{array}$ & 140 & $<1$ & 4 & Wheezing & OR 1.4 (0.7 to 2.9$)$ & 7 \\
\hline $\begin{array}{l}\text { Teeratakulpisarn et a } \mathbb{R}^{1} \text { (respiratory } \\
\text { pathogens study) }\end{array}$ & 2014 & Thailand & 170 & $1-24$ & $5-7$ & Asthma & HR 1.34 (0.26 to 6.95$)$ & 8 \\
\hline Takeyama et al ${ }^{15}$ (paediatric patients cohort) & 2014 & Japan & 153 & $\leq 36$ & $3-6$ & Wheezing & RR 1.66 (1.145 to 2.4$)$ & 7 \\
\hline de Winter et $a^{P^{3}}$ (healthy birth cohort study) & 2015 & $\begin{array}{l}\text { The } \\
\text { Netherlands }\end{array}$ & 290 & Newborns & 3 & Wheezing & OR 9.7 (3.1 to 33.5$)$ & 8 \\
\hline
\end{tabular}


Study

ID
$\%$

Weight

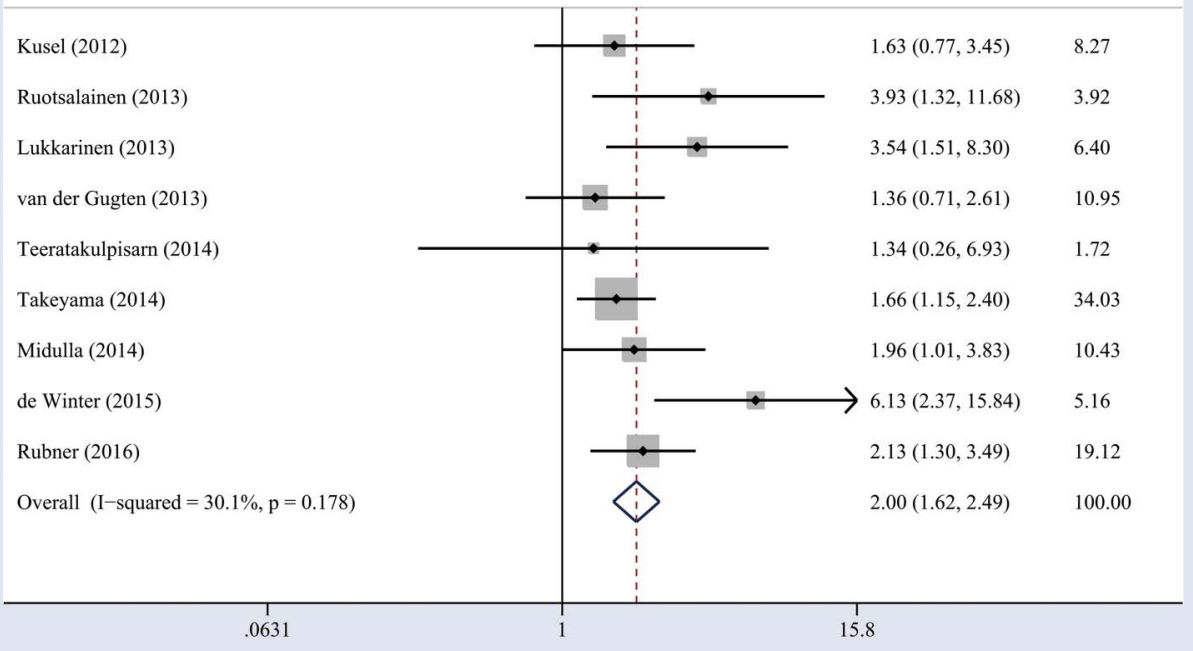

Figure 2 Forest plot of the overall association between RV-induced wheezing in the first 3 years of life and the subsequent development of wheezing/asthma. RR, relative risk; RV, rhinovirus.

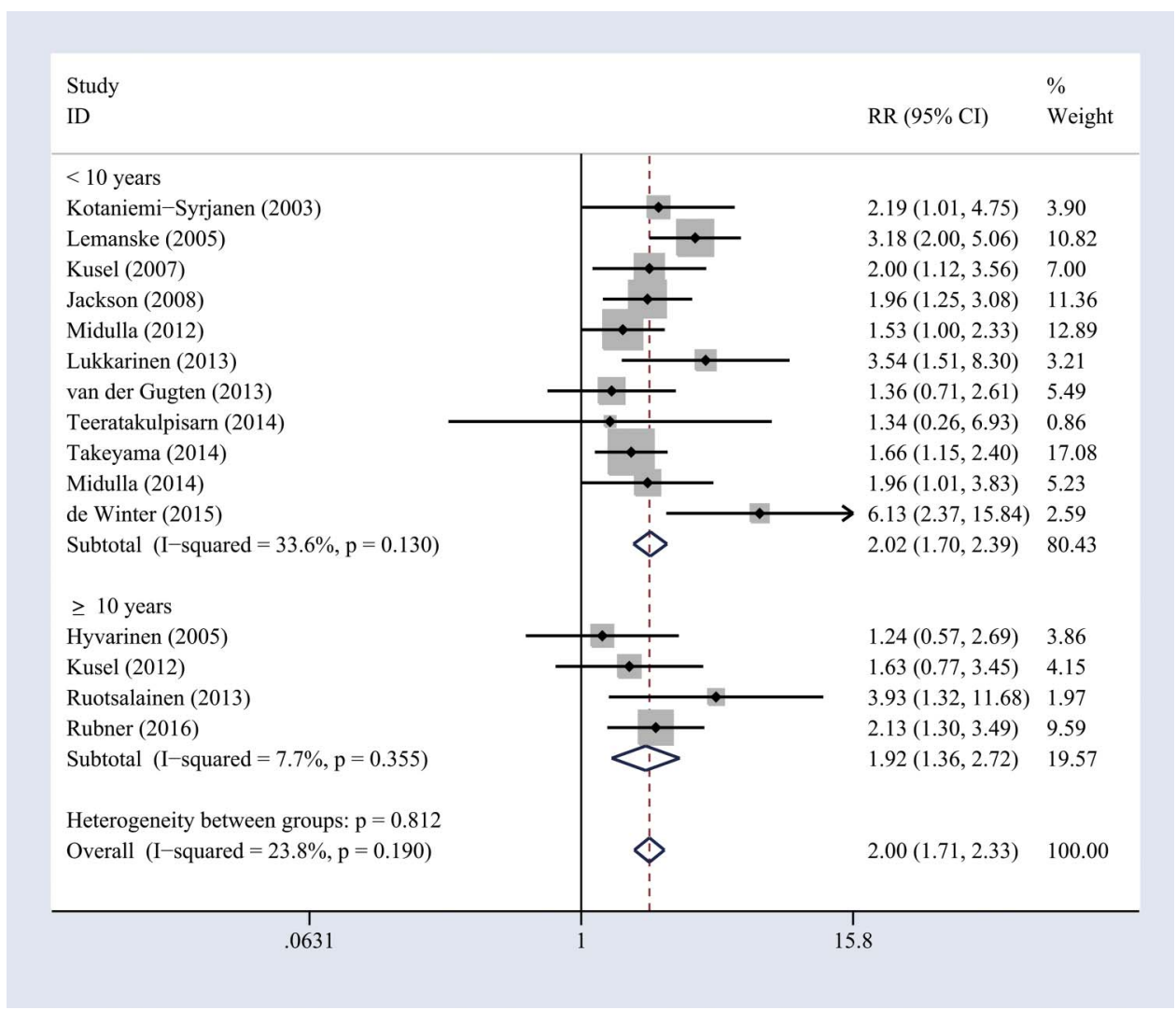

Figure 3 Forest plot of the association between early life RV wheezing illness and later onset of wheezing/asthma, stratified by age at follow-up. RR, relative risk; RV, rhinovirus. 
Figure 4 Funnel plot of publication bias for the association between early-life RV wheezing illness and later onset of wheezing/asthma. The horizontal axis represents InRR and the vertical axis means the SE of InRR. Vertical line and sloping lines in funnel plot represent summary $\mathrm{RR}$ and expected $95 \% \mathrm{Cl}$ for a given $\mathrm{SE}$, respectively. InRR, natural logarithm of the $R R$; $R R$, relative risk; $\mathrm{RV}$, rhinovirus.
Funnel plot with pseudo 95\% confidence limits

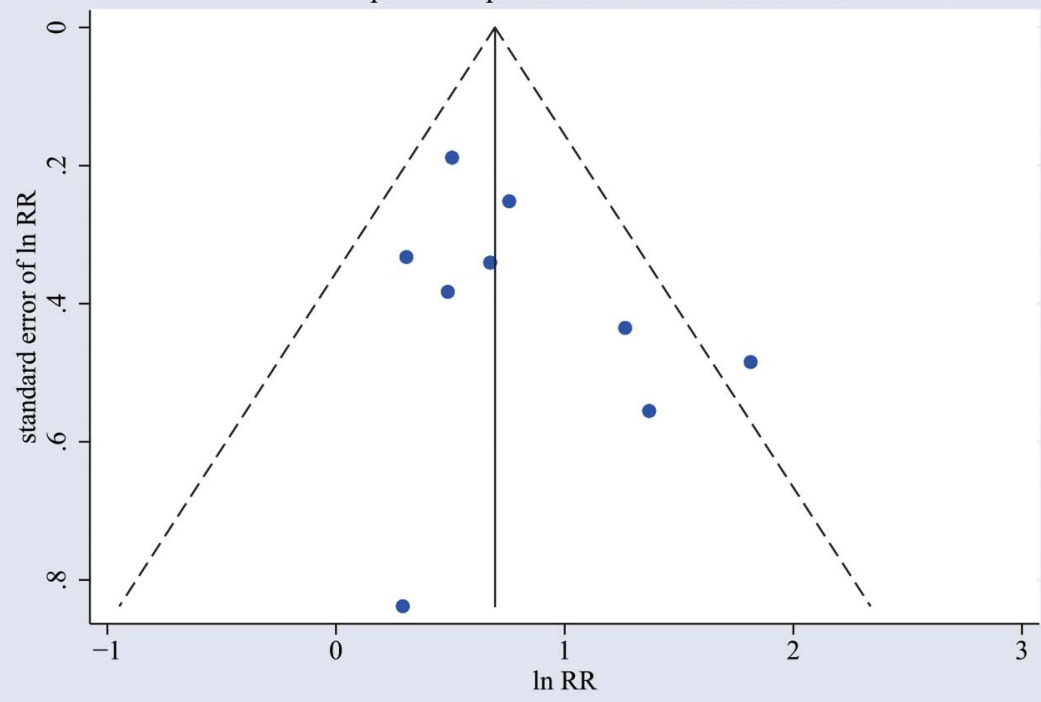

\section{Sensitivity and publication bias analysis}

A sensitivity analysis that excluded all studies for which the OR to RR conversion was used had a similar result, with a pooled RR of 1.81 (95\% CI 1.34 to 2.45 , p<0.001). The funnel plot was used to evaluate publication bias, and there was no obvious asymmetry (figure 4). Furthermore, no significant publication bias was detected by Begg's and Egger's test $(p>0.05)$.

\section{DISCUSSION}

Previous studies have shown that the RV wheezing illness in early life may increase subsequent wheezing/asthma risk, but they did not include all relevant studies and were only simple descriptive analyses. ${ }^{12} 24 \quad 41$ In the present meta-analysis, we combined eligible studies to yield summary results, which indicated that RV wheezing illness in the first 3 years was associated with subsequent development of wheezing/asthma in overall analysis. A recent study has shown that the association between RSV hospitalisation and wheezing/asthma decreases with age at follow-up. ${ }^{42}$ To evaluate whether the association between RV wheezing illness and the subsequent development of wheezing/asthma would also change with age, we included all the studies $(n=15)$ containing the same cohorts with different follow-up periods to perform subgroup analysis stratified by age at follow-up, and the association still remained significant in $<10$ years and $\geq 10$ years, suggesting that the pathophysiological mechanisms and progress of RV infection might be different from that of RSV infection. The main problem with cohort studies is confounding, which might lead to biased results. ${ }^{43}$ For example, atopy may be a confounding factor, which has been defined as a pivotal risk factor for RV wheezing illness and the development of asthma. $^{18}{ }^{44}$ Jackson et $a l^{19}$ and Rubner et $a l^{36}$ have indicated that adjustment for atopy does not alter the impact of RV wheezing on subsequent asthma development, while Kusel et $a l^{25}$ have indicated that association of RV wheezing with asthma is restricted to children who developed atopic sensitisation before or after the age of 2 years when the follow-up is for 5 or 10 years. ${ }^{37}$ Further studies are needed to evaluate whether atopy is a confounding factor or interacts with RV infection. Although the results of some studies included in our meta-analysis were adjusted for factors which might alter the association between RV wheezing and wheezing/ asthma risk (see online supplementary table S2), not every study was adjusted and not all potential confounding factors were included, so we should interpret our results more cautiously.

$\mathrm{RV}$, which is a small (30 $\mathrm{nm}$ in diameter) non-enveloped virus containing single-stranded RNA that can be translated directly into protein (positive strand), was originally discovered in the 1950s. Advances in virological detection techniques have led to the identification of RV as a major cause of wheezing illness in infants and young children. Recently, a growing number of studies explore the association between RV-induced early wheezing and the development of subsequent wheezing and asthma. ${ }^{14} \quad 15 \quad 18-23 \quad 25 \quad 35-40$ However, the results are inconclusive. Therefore, it is critical to systematically evaluate all relevant studies and to assess the overall association. In the present meta-analysis, the combined results demonstrated that RV wheezing illness in the first 3 years of life was associated with the subsequent development of wheezing/asthma. There are several mechanisms underlying the association between RV wheezing illness in the earlier life stage and the subsequent development of wheezing/asthma. First, RV infections may increase airway sensitisation by altering the epithelial barrier. ${ }^{45}$ Second, RV can induce epithelial release of 'novel innate cytokines' (TSLP, interleukin (IL)-25 and IL-33), which creates a permissive 
environment for type 2 differentiation of dendritic cells, $\mathrm{T}$ cells and innate lymphoid cells, leading to production of the proasthmatic cytokines IL-4, IL-5 and IL-13. ${ }^{46}$ Finally, RV infection can upregulate the expression of genes that may increase susceptibility of asthma. ${ }^{47}$ These findings demonstrate that $\mathrm{RV}$ infection can activate a number of pathways that may have deleterious effects on the rapidly growing airways of young children.

Previous studies have shown that RV wheezing illness is a strong predictor of subsequent wheezing/asthma, generally in two types of high-risk cohorts: early wheezing children with an atopic background and/or children hospitalised for early wheezing. ${ }^{15}{ }^{18-22} 25$ However, the role of RV in healthy infants lacking an a priori increased risk of asthma is unknown. One study ${ }^{23}$ included in our meta-analysis was carried out in a low-risk cohort (children of parents without asthma, who were not hospitalised for infant wheezing illness), and the findings were consistent with results of the previous studies, suggesting that RV-induced wheezing in early life is a risk factor for subsequent development of wheezing/asthma in high-risk and low-risk children. Further research will identify and protect the young children at increased risk for RV wheezing illness.

Effective strategies against RV could prevent the development of early-life RV wheezing illness as well as attenuate the consequences of the immune response to the pathogen, which may reduce asthma risk. Unfortunately, RV therapeutics are currently not available mainly because of the wide variety of RV subtypes and poor cross-protection from prior heterologous infections. For therapeutic and prevention research to advance, future studies first need to identify the most pathogenic RV species, which then can be the focus of the future research to develop effective interventions.

Several limitations should also be taken into account when interpreting our results: (1) the number of studies and participants included in the present meta-analysis was relatively small. (2) RV diagnosis relies almost entirely on PCR because this virus is difficult to culture, there are no antigen detection tests available and serology is infeasible. ${ }^{24}$ PCR is a quite sensitive approach to detect virus infection; it should not miss any RV infection. However, the high sensitivity of PCR might cause false-positive results, as the presence of virus nucleic acid in respiratory secretions of patients with respiratory symptoms does not prove that the virus is the cause of the symptoms. (3) The diagnosis of wheezing/asthma was not always provided by a physician, which might affect the accuracy of the diagnosis and create a bias; even if the diagnosis was made by a physician, it is not clear whether the physician was blind to the presence or absence of RV disease in the first 3 years. (4) In the studies included in our meta-analysis, disease outcome was often measured in non-categorical variables, such as the frequency of wheezing episodes and lung function. However, researchers always converted these noncategorical variables into a categorical variable (healthy condition, with childhood wheezing/asthma or not), which would cause the loss of information. (5) We could not confirm whether parents gave reliable information. (6) The causes of wheezing are not always identical to those of asthma. However, the children with wheezing in the earlier stage of life will easily suffer from asthma, and some children with early-onset asthma will get better with time, so it is difficult to distinguish between wheezing and asthma. (7) It is commonly thought that asthma is a multifactorial disease resulting from complex interactions between genetic predisposition and environmental factors, so the association of RV wheezing with asthma would be affected by ethnic origin. However, we were not able to evaluate the interaction effect of genetic backgrounds by wheezing because there were only two studies in Asians. In addition, although the results of some studies included in our meta-analysis were adjusted for some factors which might alter the association between RV wheezing and wheezing/asthma risk, there were still other potential influencing factors. (8) NOS is a commonly used tool for quality assessment of non-randomised studies included in a systematic reviewer and/or analysis, however, use it may be controversial as the summary scores involve inherent weight of component items. No matter estimated effect varies with the quality score or not, the analyst can skip the quality score analysis and go straight to the quality component analysis to find out which components are responsible for the variation or avoid the risk of misleading conclusions; therefore, some researchers think that quality score analysis may be superfluous. ${ }^{48}$ (9) Some data were not presented in the paper and were not obtained from the original researchers, so we could only derive unadjusted data using formulas or use the data obtained from another similar study, which may lead to biased results. (10) In subgroup analysis by age at follow-up, we included all the studies $(n=15)$ containing the same cohorts with different follow-up periods. The estimates from one study will be correlated, which will result in SEs (and corresponding 95\% CIs) that do not reflect the true variability. (11) Potential publication bias is also a concern. Although we did not observe apparent publication bias by statistical tests, it was still difficult to completely rule out this problem because there were not enough studies to detect it adequately.

\section{CONCLUSIONS}

In conclusion, the current meta-analysis indicates that $\mathrm{RV}$ wheezing illness in the first 3 years may be associated with subsequent development of wheezing/asthma. Clinical studies attempting to identify the young children at increased risk for RV wheezing illness and the most pathogenic RV species are ongoing and critical to the development of therapeutic and prevention strategies. More large-size prospective studies that adequately address concerns for potential confounding factors (sex, 
lung function, atopy, etc) are required to validate the risk identified in the current meta-analysis.

Contributors LL, YP and ML were involved in conception and design. LL, YP, $Y Z, Y S, X S$ and $L Y$ were responsible for obtaining and preparing the data. YZ and $Y S$ conducted the statistical analysis. LL drafted the initial version of the manuscript and all authors contributed to revision. $\mathrm{ML}$ is the guarantor of this work.

Funding This work was supported by the National Natural Science Foundation of China (grant numbers 81330002 and 81670051).

Competing interests None declared.

Provenance and peer review Not commissioned; externally peer reviewed.

Data sharing statement No additional data are available.

Open Access This is an Open Access article distributed in accordance with the Creative Commons Attribution Non Commercial (CC BY-NC 4.0) license which permits others to distribute, remix, adapt, build upon this work noncommercially, and license their derivative works on different terms, provided the original work is properly cited and the use is non-commercial. See: http:// creativecommons.org/licenses/by-nc/4.0/

\section{REFERENCES}

1. Asher I, Pearce N. Global burden of asthma among children. Int J Tuberc Lung Dis 2014;18:1269-78.

2. Asher MI, Stewart AW, Mallol J, et al. Which population level environmental factors are associated with asthma, rhinoconjunctivitis and eczema? Review of the ecological analyses of ISAAC phase one. Respir Res 2010:11:8.

3. Cookson W, Moffatt M, Strachan DP. Genetic risks and childhoodonset asthma. J Allergy Clin Immunol 2011;128:266-70. quiz 71-2.

4. Inoue Y, Shimojo N. Epidemiology of virus-induced wheezing/ asthma in children. Front Microbiol 2013;4:391.

5. Rosenthal LA, Avila PC, Heymann PW, et al. Viral respiratory tract infections and asthma: the course ahead. J Allergy Clin Immunol 2010;125:1212-17.

6. Okayama Y. Cellular and humoral immunity of virus-induced asthma Front Microbiol 2013;4:252.

7. Sigurs N, Aljassim F, Kjellman B, et al. Asthma and allergy patterns over 18 years after severe RSV bronchiolitis in the first year of life. Thorax 2010;65:1045-52.

8. Lauinger IL, Bible JM, Halligan EP, et al. Patient characteristics and severity of human rhinovirus infections in children. $J$ Clin Virol 2013:58:216-20.

9. Turunen R, Koistinen A, Vuorinen $\mathrm{T}$, et al. The first wheezing episode: respiratory virus etiology, atopic characteristics, and illness severity. Pediatr Allergy Immunol 2014;25:796-803.

10. Gern JE. The ABCs of rhinoviruses, wheezing, and asthma. J Virol 2010;84:7418-26.

11. Stone CA Jr, Miller EK. Understanding the association of human rhinovirus with asthma. Clin Vaccine Immunol 2016;23:6-10.

12. Jackson DJ. The role of rhinovirus infections in the development of early childhood asthma. Curr Opin Allergy Clin Immunol 2010;10:133-8.

13. Miller EK, Lu X, Erdman DD, et al. Rhinovirus-associated hospitalizations in young children. $J$ Infect Dis 2007;195:773-81.

14. van der Gugten AC, van der Zalm MM, Uiterwaal CS, et al. Human rhinovirus and wheezing: short and long-term associations in children. Pediatr Infect Dis J 2013;32:827-33.

15. Takeyama A, Hashimoto $K$, Sato M, et al. Clinical and epidemiologic factors related to subsequent wheezing after virus-induced lower respiratory tract infections in hospitalized pediatric patients younger than 3 years. Eur J Pediatr 2014;173:959-66.

16. Jartti $\mathrm{T}$, Lehtinen $\mathrm{P}$, Vuorinen $\mathrm{T}$, et al. Bronchiolitis: age and previous wheezing episodes are linked to viral etiology and atopic characteristics. Pediatr Infect Dis J 2009;28:311-17.

17. Rakes GP, Arruda E, Ingram JM, et al. Rhinovirus and respiratory syncytial virus in wheezing children requiring emergency care. IgE and eosinophil analyses. Am J Respir Crit Care Med 1999;159:785-90.

18. Hyvarinen MK, Kotaniemi-Syrjanen A, Reijonen TM, et al. Teenage asthma after severe early childhood wheezing: an 11-year prospective follow-up. Pediatr Pulmonol 2005;40:316-23.
19. Jackson DJ, Gangnon RE, Evans MD, et al. Wheezing rhinovirus illnesses in early life predict asthma development in high-risk children. Am J Respir Crit Care Med 2008;178:667-72.

20. Lukkarinen $\mathrm{M}$, Lukkarinen $\mathrm{H}$, Lehtinen $\mathrm{P}$, et al. Prednisolone reduces recurrent wheezing after first rhinovirus wheeze: a 7-year follow-up. Pediatr Allergy Immunol 2013:24:237-43.

21. Teeratakulpisarn J, Pientong C, Ekalaksananan T, et al. Rhinovirus infection in children hospitalized with acute bronchiolitis and its impact on subsequent wheezing or asthma: a comparison of etiologies. Asian Pac J Allergy Immunol 2014;32:226-34

22. Midulla F, Nicolai A, Ferrara M, et al. Recurrent wheezing 36 months after bronchiolitis is associated with rhinovirus infections and blood eosinophilia. Acta Paediatr 2014;103:1094-9.

23. de Winter JJ, Bont L, Wilbrink B, et al. Rhinovirus wheezing illness in infancy is associated with medically attended third year wheezing in low risk infants: results of a healthy birth cohort study. Immun Inflamm Dis 2015;3:398-405.

24. Kieninger $\mathrm{E}$, Fuchs $\mathrm{O}$, Latzin $\mathrm{P}$, et al. Rhinovirus infections in infancy and early childhood. Eur Respir J 2013;41:443-52.

25. Kusel MM, Kebadze T, Johnston SL, et al. Febrile respiratory illnesses in infancy and atopy are risk factors for persistent asthma and wheeze. Eur Respir J 2012;39:876-82.

26. Moher D, Liberati A, Tetzlaff $\mathrm{J}$, et al. Preferred reporting items for systematic reviews and meta-analyses: the PRISMA statement. Ann Intern Med 2009;151:264-9. w64.

27. Stang A. Critical evaluation of the Newcastle-Ottawa scale for the assessment of the quality of nonrandomized studies in meta-analyses. Eur J Epidemiol 2010;25:603-5.

28. Zhang J, Yu KF. What's the relative risk? A method of correcting the odds ratio in cohort studies of common outcomes. JAMA 1998;280:1690-1.

29. McNutt LA, Wu C, Xue $X$, et al. Estimating the relative risk in cohort studies and clinical trials of common outcomes. Am J Epidemiol 2003:157:940-3.

30. Greenland S. Model-based estimation of relative risks and other epidemiologic measures in studies of common outcomes and in case-control studies. Am J Epidemiol 2004;160:301-5.

31. Miettinen O. Estimability and estimation in case-referent studies. Am J Epidemiol 1976;103:226-35.

32. Higgins J, Green S. Cochrane handbook for systematic reviews of interventions. John Wiley \& Sons, Ltd, 2008.

33. Begg CB, Mazumdar M. Operating characteristics of a rank correlation test for publication bias. Biometrics 1994;50:1088-101.

34. Egger M, Davey Smith G, Schneider M, et al. Bias in meta-analysis detected by a simple, graphical test. $B M J$ 1997;315:629-34.

35. Ruotsalainen M, Hyvarinen MK, Piippo-Savolainen E, et al. Adolescent asthma after rhinovirus and respiratory syncytial virus bronchiolitis. Pediatr Pulmonol 2013;48:633-9.

36. Rubner FJ, Jackson DJ, Evans MD, et al. Early life rhinovirus wheezing, allergic sensitization, and asthma risk at adolescence. $J$ Allergy Clin Immunol 2016;139:501-7.

37. Kusel MM, de Klerk NH, Kebadze T, et al. Early-life respiratory viral infections, atopic sensitization, and risk of subsequent development of persistent asthma. J Allergy Clin Immunol 2007:119:1105-10.

38. Midulla F, Pierangeli A, Cangiano G, et al. Rhinovirus bronchiolitis and recurrent wheezing: 1-year follow-up. Eur Respir $J$ 2012;39:396-402.

39. Lemanske RF Jr, Jackson DJ, Gangnon RE, et al. Rhinovirus illnesses during infancy predict subsequent childhood wheezing $J$ Allergy Clin Immunol 2005;116:571-7.

40. Kotaniemi-Syrjanen A, Vainionpaa R, Reijonen TM, et al. Rhinovirus-induced wheezing in infancy-the first sign of childhood asthma? J Allergy Clin Immunol 2003;111:66-71.

41. Beigelman A, Bacharier LB. Early-life respiratory infections and asthma development: role in disease pathogenesis and potential targets for disease prevention. Curr Opin Allergy Clin Immunol 2016;16:172-8.

42. Regnier SA, Huels J. Association between respiratory syncytial virus hospitalizations in infants and respiratory sequelae: systematic review and meta-analysis. Pediatr Infect Dis $J$ 2013;32:820-6.

43. Egger M, Schneider M, Davey Smith G. Spurious precision? Meta-analysis of observational studies. BMJ 1998;316:140-4

44. Korppi M, Piippo-Savolainen E, Korhonen K, et al. Respiratory morbidity 20 years after RSV infection in infancy. Pediatr Pulmonol 2004;38:155-60. 
45. Rossi GA, Colin AA. Infantile respiratory syncytial virus and human rhinovirus infections: respective role in inception and persistence of wheezing. Eur Respir J 2015;45:774-89.

46. Feldman AS, He Y, Moore ML, et al. Toward primary prevention of asthma. Reviewing the evidence for early-life respiratory vira infections as modifiable risk factors to prevent childhood asthma. Am J Respir Crit Care Med 2015;191:34-44.
47. Proud D, Turner RB, Winther B, et al. Gene expression profiles during in vivo human rhinovirus infection: insights into the host response. Am J Respir Crit Care Med 2008;178: 962-8.

48. Greenland S. Quality scores are useless and potentially misleading-reply to re-a critical-look at some popular analytic methods. Am J Epidemiol 1994;140:300-1. 